\title{
Designing and Experiencing the Family Business Advisory
}

\section{Marta Widz}

KEYWORDS: Family Business, Consulting, advisory, family business trusted advisor.

This exercise gives students hands-on experience as family business advisors. Students are presented with a case of a family business and are required to take the role of various types of advisors; i.e. informal, formal, and boards. Together then learn to understand a family business's complexity and unfold its underlying, often hidden, dynamics. They also decide on the most appropriate family business advisory role: counseling \& mediating, facilitating \& consulting, or mentoring \& coaching. Finally, they design an advisory intervention and provide detailed steps in the advisory process, then reflect on it.

This exercise can work successfully with undergraduate, graduate, and executive education students, if they have some basic understanding of family business principles. We recommend that students gain that knowledge through either taking a family business course or actually serving as an owner, future leader, family member or employee in an established family firm. Students work in teams of 3 - 5, forming the family business advisory groups. The exercise is an effective way to experience what it means to be an advisor to family business just within 120 minutes. It can be successfully used for both in-class learning and in an online course.

Download the supporting document with this article (above) for classroom materials.

\section{Complexities of Family Businesses}

Family businesses, the dominant form of the enterprise worldwide, are known for their complexities. "Due to the inextricable link between family and business, family firms must grapple with unique issues and decisions (...). In particular, family businesses are greatly concerned with succession planning, transferring wealth to the next generation, managing conflict, sibling rivalry, entitlement, hiring and managing family and non-family employees,facilitating growth and change, and maintaining family values and culture." (Eddleston,

\author{
2016, p. 1).
}

\section{The Role of Advisors}

Advisors can play a crucial role in family businesses. They influence strategic decisions (Strike, 2012), encourage family cohesion, and provide access to the networks that encourage community embeddedness. (Holt, Pearson, Carr \& Barnett, 2016; Michel \& Kammerlander, 2015; Reay et al., 2013).

They also face some unique challenges, including trying to navigate the complexities of the family business system and understanding its underlying, often hidden, dynamics. Those advisors who are able to get close enough to the family and achieve "embeddedness" (Barbera \& Hasso, 2013) become the most trusted advisors, as first labeled by Strike (2012). Trusted advisors embrace the complexities; and thus, they provide innovative solutions to a family business's complex problems by bringing an outside, more objective perspective (Lane, Astrachan, Keyt \& McMillan, 2006).

\section{Types of Family Advisors}

Family businesses may depend on three types of advisors: informal advisors, formal advisors, and family firm boards (Strike, 2012).

Informal advisors - such as spouses, close friends, or business partners - often provide informal advice (Strike, 2012) and are the largest group of advisors (Boyd, Upton \& Wircenski, 1999). Formal advisors, who are paid for their services, are content experts in areas such as accounting and taxes; or process specialists experienced in certain processes such as succession or change management (Kaye \& Hamilton, 2004). A board of directors or advisory board is the most complex type of advisor organization, especially in the family-owned SMEs. These members have a longstanding, trustbased relationship with key family business owners. The type of advisor frames the advisory intervention and may define which advisory role is consulted.
Copyright (C) 2020 The Authors. Entrepreneur \& Innovation Exchange is published at EIX.org. This is an open access article under the terms of the Creative Commons Attribution-NoDerivs License, which permits use and distribution in any medium, provided the original work is properly cited and no modifications or adaptations are made. View EIX.org Authorship Terms at https://eix.org/terms
FamilyBusiness 


\section{Advisory Roles}

In order to manage the family and the business issues, advisors must know how to listen actively, show empathy, reframe and set frames, create a commitment, reconcile or provide structures. They must be able to take on various family business advisory roles (refer to Table 1 in the supporting document; available above for download), such as (i) counseling \& mediating, (ii) facilitating \& consulting, or (iii) mentoring \& coaching. Based on the issues the family business and the enterprising family are facing, the advisory intervention can aim at:

- Healing and reconciliation with counseling \& mediating;

- Creating and providing solutions with facilitating \& consulting,

- Building capacities and competencies with mentoring \& coaching

Every advisory role requires the advisors be proficient at a specific set of competencies.

\section{Description of the Exercise}

The purpose of this experiential learning exercise is to give students hands-on experience on the complexity of the family business advisory, which reflects the complexity of a family business system. Potential learning outcomes include:

- Deep understanding of a family business system, the complexity of family business' issues, and the ability to discover and grasp some underlying, often hidden, dynamics.

- Understanding the spectrum of advisory interventions provided by various types of advisors, i.e. informal,formal, and boards.

- Hands-on experience in designing the advisory intervention by reaching out to the various family business advisory roles, (i) counseling \& mediating, (ii) facilitating \& consulting, (iii) mentoring \& coaching.

- Understanding which type of an advisor and family business advisory role can address the specific issues in the family business system.

\section{Exercise Steps and Timing}

The exercise includes the following steps, with an estimated time of 140 to 160 minutes (if the complexity of only one family business is analyzed), excluding the advance preparation.

1) Advance preparation: deep dive into the complexity of a family business' system by using one of the following:

- Any family business can be used for this part of the exercise, provided it meets the following definition: The family business is a business governed and/or managed with the intension to shape and pursue the vision of the business held by a dominant coalition controlled by members of the same family or small number of families in a manner that is potentially

sustainable across generations of the family or families (Chua, Chrisman and Sharma, 1999, p. 25).

- "Real-Life Drama: Creating a TV Series Based on a Family Business" exercise (refer to Eddleston, 2016; and Figure 2 in the supporting document). If that option is chosen,"

Experiencing the Complexity of the Family Business Advisory" would create a series of experiential learning exercises that build on one another, with a TV series being a module 1 , and family business advisory a module 2 .

- A family business case (for a list of case studies depicting family businesses, refer to De Massis \& Kotlar, 2019 in the supporting document).

- A movie featuring a family business (for a list of movies depicting family businesses, refer to Table 4 in the supporting document).

2) Introduction to the exercise and the complexity of family business advisory (10 minutes), including the theory on:

- the types of advisors, i.e. informal, formal and boards,

- family business advisory roles, (i) counseling \& mediating, (ii) facilitating \& consulting, (iii) mentoring \& coaching. 10 minutes.

3) Assigning/selecting the teams of 3-to-5 students and assigning the type of advisor -- informal, formal, and boards -- by drawing a card as if in the lottery, if the exercise is used in a classroom, or by assigning the type of advisor to a breakout room, if exercise is conducted online (5 minutes). This step ensures that all three types of advisors are represented in a class, which lets students compare the interventions proposed by the 
various types of advisors.

4) Understanding the family business complexity and issues (20 to 40 minutes)

- Pitch of a TV series on the family business by student teams, if this exercise builds a series of experiential learning exercises together with "Real-Life Drama: Creating a TV Series Based on a Family Business" (20 minutes).

- Analysis of the family business complexity, i.e. discussion on the underlying issues depicted in the TV series, in a case study, or the movie depicting a family business (20 minutes).

5) Designing the advisory intervention - group work in physical or virtual breakout rooms (60 minutes), which includes:

- Listing the family business issues and discussion around why they emerged,

- Discussing how the issues could be tackled and with what advisory role: (i) counseling \& mediating, (ii) facilitating \& consulting, (iii) mentoring \& coaching.

- Discussing how the assigned type of advisor, i.e. informal, formal, and boards, frames the possible advisory role and deciding on the advisory role.

- Planning the steps in the advisory process and reflecting on why and how the chosen intervention would help the family and the business overcome and manage the identified issues.

- Identifying the alternative intervention process forecasting the problems that may emerge in the process.

6) Presentation of the advisory intervention in the class and Q\&A. If this exercise is coupled with "RealLife Drama: Creating a TV Series Based on a Family Business," students who pitched the TV series continue to play the roles of members of the family business and actively ask the questions to the students' advisory team. (30 minutes per family business case: 20 minutes presentation plus 10 minutes $Q \& A$ session)

7) Debriefing. Moderated class discussion of all advisory interventions, including the reflection on the advisory types and advisory roles (15 minutes)

\section{Instructor's Guidelines and Guiding Questions}

The following are the suggested guiding questions and supporting material, which may help the facilitators run the exercise smoothly:

Step 2 of the exercise: "Introduction to the exercise and the complexity of family business advisory, including the theory on the types of advisors and family business advisory roles":

- Provide students with a basic understanding of the type of advisors and advisory roles. From the supporting document, distribute or show Table 1: Type of advisors: informal, formal, boards, and Table 2: Family business advisory roles of (i) counseling \& mediating, (ii) facilitating \& consulting, (iii) mentoring \& coaching.

Step 3 of the exercise: Assigning/selecting the teams of 3 to 5 students and assigning the type of advisor":

- If the exercise is used in the classroom: From the "Students pack," (See supporting document) print enough cards depicted in "Figure 1: Type of Advisors" for all your advisory teams. Cut the cards as the lottery ticket. Ask every students' advisory team to draw one card.

- If exercise is used online: create enough virtual breakout rooms for each advisory team. Assign either informal,formal, or boards type of advisors to every of the break-out room and instruct the students which advisory team shall join which break-out room (5 minutes).

Step 4 of the exercise: "Understanding the family business complexity and issues." In a moderated class discussion, analyze the complexity of the family business system. Students receive the time to ask questions to gain a deep understating of the issues and underlying patterns. If this exercise is conducted as a module 2 of the exercise series (together with the "RealLife Drama: Creating a TV Series Based on a Family Business" exercise), the questions shall be directed at the team of students who are pitching a TV series. Otherwise, uncovering the family business issues takes the form of a class discussion.

Possible questions may include: 
- Who are the main players?

- What are the goals of the family? Business? Owners?

- What is the role of the key protagonists in solving the issue?

- Who else, apart from the key protagonists featured in the family business, does play a role?

- Why did the depicted issue happen?

- What could have been done to avoid the issue?

Step 5 of the exercise: "Designing the advisory intervention" is group work (in physical or virtual breakout rooms), in which the teams of 3-5 students form the advisory group. From the "Students pack," (See supporting document) distribute or show Table 3: Steps to follow while designing the advisory intervention. We recommend that instructors observe the work of groups (visit the physical or virtual breakout rooms) and facilitate the work of students. Possible questions that the instructor may ask to assist the students in designing the detailed steps in the advisory process:

- Which person from the family business should you approach first? Second? Third?

- What questions would you ask and to whom?

- Would you consider individual intervention or a group one?

- How would you capitalize on the "hidden" protagonists?

- What steps would you recommend to the key protagonists in solving the issue?

- Should other types of advisors get involved in the project to work along with your advisory group?

- What are your proposed timelines for each step of the advisory intervention?

- How would you measure the success of your advisory intervention?

- When would you stop working on that advisory intervention project

Step 6 of the exercise: "Presentation of the advisory intervention in the class and Q\&A." If this exercise is coupled with "Real-Life Drama: Creating a TV Series Based on a Family Business," students who pitched the TV series continue to play the role of members of the family business and take the lead in asking the questions to the students advisory team. Otherwise, the instructor serves as the moderator of a class discussion in the Q\&A part. Possible questions may include:

- How did you identify the family business issues? Have you used any frameworks, models, etc.?

- How and why did you choose that specific advisory role: (i) counseling \& mediating, (ii) facilitating \& consulting, (iii) mentoring \& coaching? For which issues?

-What made you think that your proposed advisory intervention would help the family and the business overcome and manage the identified issues?

- Have you identified any plans $B$ and $C$ in case your plan A would not work?

Step 7 of the exercise: "Debriefing" is a post-advisory reflection of all advisory interventions collectively. The instructor drives the class discussion, in which the advisory groups reflect on their advisory intervention and especially on how the assigned advisory type (i.e. informal advisor, formal advisor, board) framed or even constrained their advisory intervention and pre-defined the family business advisory role (i.e. (i) counseling \& mediating, (ii) facilitating \& consulting, (iii) mentoring \& coaching). Possible questions that may steer that reflection include:

- Which advisor group intervention was the most effective one? Why?

- Under what circumstances could you apply such an intervention in other family businesses /enterprising families?

- How different would your advisory intervention be if you were to step into the shoes of a different type of an advisor, e.g. boards instead of informal advisors?

- If you had a free choice, which advisory type and family business advisory role would you chose for this family business/this enterprising family? Why?

\section{References}

Barbera, F., \& Hasso, T. (2013). Do we need to use an accountant? The sales growth and survival benefits to family SMEs. Family Business Review, 26(3), 271-292.

Boyd, J., Upton, N., \& Wircenski, M. (1999). Mentoring in family firms: A reflective analysis of senior executives' perceptions. Family Business Review, 12(4), 299-309.

Chua, J. H., Chrisman, J. J., \& Sharma, P. (1999). 
Defining the family business by behavior. Entrepreneurship Theory and Practice, 23(4), 19-39.

De Massis, A., \& Kotlar, J. (2019, March 15). Case Studies, Movies, TV Shows and Other Family Business Resources. Entrepreneur \& Innovation Exchange. Published online at FamilyBusiness.org. doi:10.32617/362-5c8bbf8788fb0

Eddleston, K. (2016, November 14). Real-Life Drama: Creating a TV Series Based on a Family Business. Entrepreneur \& Innovation Exchange. Published online at FamilyBusiness.org. doi:10.17919/X9KG6V

Holt, D. T., Pearson, A. W., Carr, J. C., Barnett, T. (2016). Family Firm(s) Outcomes Model: Structuring Financialand Nonfinancial Outcomes across the Family and Firm. Family Business Review. Forthcoming.

Kaye, K., \& Hamilton, S. (2004). Roles of trust in consulting to financial families. Family Business Review, 17(2), 151-163.

Lane, S., Astrachan, J., Keyt, A., \& McMillan, K. (2006). Guidelines for family business boards of directors. Family Business Review, 19(2), 147-167.

Michel, A., \& Kammerlander, N. (2015). Trusted advisors in a family business's succession- planning process-An agency perspective. Journal of Family Business Strategy, 6(1), 45-57.

Mickel, M., McVeigh, N., \& Leger, S. (2018). Practitioners' Spectrum. Family Firm Institute Annual Conference.London.

Reay, T., Pearson, A. W., \& Dyer, W. G. (2013). Advising family enterprise: Examining the role of family firm advisors. Family Business Review, 26(3), 209-214.

Strike, V. M. (2012). Advising the Family Firm: Reviewing the Past to Build the Future.Family Business Review, 25,156-177.

Widz, M., \& Michel, A. (2018). Family Firms Advisors and Engagement in Radical Innovation. Academy of Management Proceedings.
(denied:applewebdata://B7320D1D-E3C1-4530-996FA6E637C312F6\#_ftnref1) 